\title{
Evolutionary Hymn
}

\author{
Arthur M. Michalek ${ }^{1}$
}

Published online: 10 October 2015

(C) American Association for Cancer Education 2015

CS Lewis penned the poem Evolutionary Hymn [1] and in the first stanza implores:

"Lead us, Evolution, lead us

Up the future's endless stair;

Chop us, change us, prod us, weed us.

For stagnation is despair:

Groping, guessing, yet progressing,

Lead us nobody knows where."

A wonderful sentiment. I begin every course that I teach with an introductory lecture in which I go over the ground rules for the course. Items include highlights of what will we cover, how they will be evaluated, and what competencies I hope that they will attain. I also explain that my course is like life and that it evolves from year to year. A course should be viewed as an entity that must evolve to survive. I apprise them that this is like their own professional and personal liveschange is inevitable. And so must it be with any Journal. Beginning this issue, I will periodically invite Associate Editors to ascend the bully pulpit to provide the main editorial of the issue. Our editors and reviewers work very hard to produce a top-flight journal. Let me say that they have been extremely successful in doing so. Recent data indicate that the impact factor of the JCE is now 1.23 whereas in 2010 it was approximately half that $(\mathrm{IP}=0.682)$. Moreover, annual assessment data from Springer demonstrates that we rank 15th of the Top 20 journals in the category Education, Scientific Disciplines. This is largely due to the quality of submissions

Arthur M. Michalek amm3@buffalo.edu

1 University at Buffalo, Buffalo, NY, USA received, as well as to the work of our reviewers and their critical review and constructive criticism. This issue's Editorial is by John Vetto, M.D. who is the deputy editor of the Journal.

Dr Vetto's editorial focuses on a review of articles recently published in the JCE in the area of colorectal cancer screening in medically vulnerable populations [2]. In his commentary, he reviews the merits of these manuscripts and highlights the strengths of divergent methodologies. He finishes by imploring us all to follow the "Platinum Rule" in the development of cancer education programs. These are thoughts that are always timely, and I found them particularly poignant as I am currently teaching a course in Evidenced Based Decision Making. The goal of the course is to provide students with the knowledge and skills to make objective decisions based on the evidence. This requires them to be conversant in a multitude of research methods and analytic skills as well as in the conduct of systematic reviews. Dr. Vetto's editorial and my experiences in this course have led me to give thought as to how we can apply these principles to cancer education and in particular to the American Association for Cancer Education. Perhaps we should follow up on these lessons by creating multiple goal-oriented learning groups to assimilate and evaluate the evidence. Such evidence-based cancer education groups could be impaneled at our annual meeting and function throughout the year and report back on their results at the next annual meeting. This would not only be of great service to the profession, but also allow for year-round interaction among the membership. Please do not hesitate to e-mail me with your thoughts and opinions at amm3@buffalo.edu.

Another slowly evolving change to the Journal is the increasing number of submissions from our non-North American colleagues. In 2012, submissions from non-North American authors represented $37 \%$ of submissions and $19 \%$ of accepted manuscripts; in 2014, submissions from non-North 
American authors increased to 45 and $23 \%$ of accepted manuscripts. These data are evident of an increasing interest in publishing in the JCE but the obvious differential between percent submissions and percent acceptances indicates a higher rejection rate. Reasons for rejection are myriad. Some submissions are not appropriate to the JCE while others suffer from methodological and language issues. We are attempting to address the latter by providing more direct mentorship to our non-North American colleagues. We are making special efforts to engage trainees from these areas. This was highlighted in my last editorial where I referenced the work of Bertha Eisses from Groningen and her mentors Drs. Chang and de Vries. Another excellent example may be found in the Reflections piece in this issue authored by Emad Shash in which he describes the Egyptian revolution in education that continues to evolve [3]. This article relates one individual's journey, the value of mentorship, and the role of evolution individually and collectively. I would urge you all to read this piece. While to date these mentoring opportunities have been informal and based upon personal interactions and serendipity, I would like to see a more formal process established. This will remain under discussion and review. Again, I would appreciate any input. Please e-mail me at amm3@buffalo.edu. And with that, I leave you with best wishes, and encouragement to read the JCE and to continue to evolve in thought and deed.

Be well!

Arthur M. Michalek, PhD, FACE

\section{References}

1. Lewis, CS. "Evoltionary Hymn" http://www.best-poems.net/c_s_ lewis/poem2677.html

2. Vetto J: colorectal cancer screening education in medically vulnerable populations: the role of the Journal of cancer education. doi: 10 . 1007/s13187-015-0922-0

3. Shash E: The evolution of undergraduate medical student research activities: Personal experience of a developing nation's up-rise. doi:10.1007/s13187-015-0923-Z 